NERUDA ANTE LA CRISIS DEL 56

\title{
Greg Dawes
}

Resumen: Este ensayo sostiene que Estravagario (1958) representa un desahogo personal y político de Neruda frente a las revelaciones de Jruschov en el XX Congreso del PCUS en 1956. Es una especie de "muerte simbólica" que enfrenta Neruda, de la que no encuentra salida en este momento dado pero que sobrevive gracias al respaldo de Matilde Urrutia y la naturaleza.

Palabras clave: Neruda; Estravagario; muerte simbólica; XX Congreso del PCUS.

Recibido: julio; aceptado: diciembre 2010.

\section{NERUDA IN THE CRISIS OF '56 Greg Dawes}

This essay holds that Estravagario (1958) was a personal and political vent of Neruda after Jruschov's revelations at the 20th Congress of the CPSU in 1956. According to Greg Dawes, it

Greg Dawes. Profesor titular de North Carolina State University y director de la revista académica A Contracorriente (www.ncsu.edu/acontracorriente). Es autor de Aesthetics and Revolution: Nicaraguan Poetry, 1979-1990 (Minnesota, 1993), Verses Against the Darkness: Pablo Neruda's Poetry and Politics (Bucknell, 2006), y Poetas ante la Modernidad: Las Ideas Estéticas y Políticas de Vallejo, Huidobro, Neruda y Paz (Editorial Fundamentos, 2009). Actualmente escribe un libro sobre la poesía y el pensamiento político de Neruda de 1956 a 1973.

Estudios Públicos, 123 (invierno 2011). 
was a sort of "symbolic death" that Neruda faced and from which he found no way out at that given moment and time, but which he survived thanks to the support of Matilde Urrutia and nature.

Keywords: Neruda, Estravagario, symbolic death, 20th Congress of the CPSU.

Received: July 2010; accepted: December 2010.

egún el consenso de la crítica, 1956 marca un hito singular en la producción poética de Neruda que la lleva más allá de la modalidad moderna que se había coronado con el Canto General. En cuanto a forma y contenido hay una rebelión "irreverente", al decir del poeta, contra su obra anterior con la publicación, dos años después, de Estravagario. La presencia de la oralidad, la ironía, el sarcasmo, el humor negro, el humor como tal, las yuxtaposiciones sorpresivas y las ilustraciones que acompañan los poemas anuncian una nueva voz poética. Sin embargo, la opinión unánime de los estudiosos de la obra nerudiana termina ahí y se presentan diferentes hipótesis sobre este cambio en la obra del vate chileno. René de Costa, por ejemplo, sostiene que en "relación con la previa postura pública de Neruda como escritor del pueblo, Estravagario parecía ser muy individualista, aún frívolo en cuanto a su ensimismamiento". Según Costa, Neruda se volvería un antipoeta que mostraría su rebeldía en la forma, y el contenido de por sí importaría menos. "Estravagario", dice, "es significativo no por su revisión política o personal del pasado cuanto por su adaptación exitosa del tono y el estilo de lo que se ha llamado la antipoesía" (176). Las características arriba mencionadas, más la desestabilización y fragmentación del sujeto poético, entonces, operarían dentro del marco de la forma. El capítulo que dedican Manuel Durán y Margery Safir al "poeta personal” también estriba en un análisis de las virtudes formales de la obra tardía de Neruda. Al igual que en el caso de Costa, la unidad de Estravagario consistiría en su "maestría del estilo, en su recién adquirida serenidad, en su elección de temas personales, y aun en la naturaleza insólita (inédita) del

${ }^{1}$ René de Costa, The Poetry of Pablo Neruda, 1979, p. 175. Traducción mía. 
grueso de los poemas en la colección"2. Para Emir Rodríguez Monegal y Jaime Alazraki, Neruda retornaría a lo esencial, a lo profético y trabaría un vínculo con su obra previa al compromiso político ${ }^{3}$. A juzgar por estos estudios, Estravagario iniciaría una nueva etapa poética que calzaría muy bien con el neovanguardismo. Se trataría de una insurrección estilística fundamentalmente sin rasgo alguno del contexto sociohistórico y político en el que se compuso este poemario.

En cambio, para Alain Sicard y Hernán Loyola las transformaciones que se desprenden de la obra tardía del poeta son manifestaciones formales y temáticas de la dura crisis personal y política que enfrenta en 1956. Para ambos críticos se trata de un momento traumático en la vida de Neruda en que se encara con las revelaciones del régimen de Stalin en la Unión Soviética por parte de Nikita Jruschov en el XX Congreso del PCUS, así como a fin de año con la invasión soviética de Hungría 4 . A esta crisis se agrega, apunta Loyola, la ruptura con Delia del Carril y la unión definitiva con Matilde Urrutia. El dolor conflictivo que aflige al poeta se liga al enojo y al sentimiento de congoja por los llamados "amigos enemigos" que lo abandonan cuando termina con Delia. Entendidas así, las características que parecieran ser neovanguardistas tienen una razón de estar vinculadas con el contexto sociohistórico, político y personal. Tanto Loyola como Sicard sostienen que a partir de 1958 el compromiso político de Neruda pasa por una metamorfosis sin cambiar fundamentalmente. A diferencia de otros comunistas que abandonaron el Partido con las revelaciones de Jruschov o con la introducción de los tanques en Budapest, anota Loyola, "Neruda no sólo no abandonó las filas de su partido sino que incluso asumió cargos y tareas del más alto nivel en el Comité Central, hasta el punto que fue el convencido y

2 Manuel Durán y Margery Safir, Earth Tones: The Poetry of Pablo Neruda, 1981, p. 116.

3 Emir Rodríguez Monegal, "El Sistema del Poeta", 1973, y Jaime Alazraki, "Poética de la Penumbra en la Poesía más Reciente de Pablo Neruda", 1973.

${ }^{4}$ Alain Sicard, “"El Hijo de la Luna’: Crítica y Valoración del Sujeto Poético en la Obra de Pablo Neruda Posterior al Canto General”, 1979, p. 322. Hernán Loyola, "Neruda Posmoderno", 2008, pp. 1-2.Véase también el interesante capítulo "Estravagario en Neruda: Construcción y Legado de una Figura Cultural”, de María Luisa Fischer, 2008, pp. 143-176. El estudio de Fischer es el primero, que yo sepa, en analizar también el papel que juegan las ilustraciones en el poemario de Neruda. 
entusiasta candidato de los comunistas chilenos a la presidencia de la república en 1969-1970"5. Se trata de una crisis que lo obliga al poeta a replantear su pensamiento político y modificarlo, pero que refuerza su compromiso con el partido.

Por eso, a mi modo de ver, habría que cuestionar el vínculo entre Estravagario y la neovanguardia, porque si Neruda retoma ciertas características que parecieran ser neo o posvanguardistas no es para adherir oficialmente a ese movimiento. Asimismo, Neruda no encaja bien si seguimos el argumento de Octavio Paz sobre la posvanguardia. Según Paz esta segunda vanguardia abarcaría a José Lezama Lima, Enrique Molina, Nicanor Parra, Jaime Sabines, Cintio Vitier, Álvaro Mutis, Roberto Juarroz y él mismo. En conjunto, estos poetas encarnarían, dice, una "vanguardia otra, crítica de sí misma y en rebelión solitaria contra la academia en que se había convertido la primera vanguardia". Capaces de "reflexionar y [de] burlarse de sí mismos: sabían que el poeta es el instrumento del lenguaje." Se vinculaban significativamente con High Modernism: con Lowell, Olson, Bishop, Ginsberg y Pessoa y al ser así creían, advierte Paz, en una "disidencia individualista y oscilaban entre el trotskismo y el anarquismo"6. En cuanto a cosmovisión y praxis estética, se confirma así el lazo entre la primera vanguardia y esta posvanguardia. Escépticos en cuanto al poder del lenguaje, relativistas en relación con la historia, y autocríticos y humorísticos, los posvanguardistas que describe Paz no distan mucho de los defensores del posmodernismo, con su inclinación por lo ahistórico (o la superficie de la historia), por lo irónico y el pastiche, el eclecticismo, su exaltación del fragmento por sobre la totalidad (telos), su desconfianza del lenguaje, y su valoración de la estética pura por sobre la política.

Sin embargo, tampoco hay que encasillar a los posvanguardistas como poetas lúdicos. No se trata de bardos que proclaman el arte por el arte posmoderno, porque sigue habiendo un anclaje en un proyecto emancipador de corte anarquista o trotskista según Paz. Esa caracterización política y artística tiene sentido ya que los estudios de Renato Poggioli, Donald G. Egbert y David Weir han señalado algunos de los vínculos entre el anarquismo y el modernismo anglosajón, y entre el

${ }^{5}$ Loyola, "Neruda Posmoderno", 2008, p. 2.

${ }^{6}$ Octavio Paz, Los Hijos del Limo: Del Romanticismo a la Vanguardia, 1998, pp. 208-210. 
pensamiento libertario y la vanguardia cultural. Si el anarquismo, como he propuesto en un libro reciente, viene a ser la expresión política e ideológica del vanguardismo histórico, no deja de ser cierto que hay una afinidad también — que identifica Paz - entre el anarquismo y el posvanguardismo ${ }^{7}$. Los parámetros de la ideología neo o posvanguardista abarcarían al liberalismo, al anarquismo y al trotskismo. Como advierte la propia trayectoria del poeta y ensayista mexicano, el posvanguardista suele adherir a una postura radical en un principio y luego pasar a una postura liberal o progresista. Al hacer eso - al adoptar los valores de la "rebelión solitaria" y la "disidencia individualista" - el pensamiento del posvanguardista se vuelve canónica y abandona gran parte de su ímpetu radical.

Como se puede apreciar, la apuesta política y estética de Neruda discrepa de los valores posvanguardistas y posmodernistas, y sirve de precursora de la otra vertiente en los años 60: los "poetas comunicantes". Es verdad que el sujeto multiforme en Estravagario emplea el humor, la ironía, es autocrítico y cuestiona sus propios principios estéticos, políticos y morales, pero no comparte el escepticismo en cuanto al lenguaje ni tampoco en cuanto al conocimiento como tal. Por añadidura, para ya enfocarme en la tesis que quiero plantear, si es cierto que la modalidad autobiográfica domina su obra tardía así como la "identidad fragmentarizada" — como la denomina Federico Schopf o "posmoderna" como lo pone Loyola - también es verdad que no predominan varias de las otras características posvanguardistas y posmodernistas en, y posteriores a, Estravagario. En su aguda periodización de la obra de Neruda, Loyola argumenta — acertadamente a mi juicio- que, como el poeta escribe en una época posmoderna, absorbe ciertas ideas y tendencias pero no comparte los valores de la ideología dominante que reina en esta fase del capitalismo. Va asumiendo así, de 1956 en adelan-

${ }^{7}$ Renato Poggioli, The Theory of the Avant-Garde, 1968, Donald G. Egbert, "The Idea of 'Avant-garde' in Art and Politics", 1967, pp. 339-366, y David Weir, Anarchy \& Culture: the Aesthetic Politics of Modernism, 1997. Elaborando las ideas de estos estudiosos, he propuesto una teoría sobre el parentesco entre el anarquismo y el vanguardismo histórico en mi libro Poetas ante la Modernidad: Las Ideas Estéticas y Politicas de Vallejo, Huidobro, Neruda y Paz, 2009, "Introducción: Modernismo, Vanguardia y Modernidad".

${ }^{8}$ Término que acuñó Mario Benedetti al titular así su libro de entrevistas con poetas de la época. Véase Los Poetas Comunicantes, 1981.

9 "La (in)certidumbre en la obra tardía de Neruda", 2004, pp. 165-193. 
te, una postura en la "posmodernidad de resistencia", que articula ideas sobre el bienestar común del socialismo después de haber hecho una crítica y autocrítica de la época de $\operatorname{Stalin}^{10}$. En ese sentido esta obra de Neruda siente las bases para y dialoga con la poesía conversacional de Roque Dalton, Nicanor Parra, Mario Benedetti, Ernesto Cardenal, Gonzalo Rojas, Juan Gelman, entre otros versistas comprometidos.

Estravagario (1958), poemario del Neruda posmoderno, representa la expresión in nuce de su crisis personal y política desatada después de las revelaciones de Jruschov en el XX Congreso del PCUS ${ }^{11}$. Lo que hallamos en este libro es el despliegue de los síntomas de esa crisis y el intento de absorber la crisis y entenderla. Se trata de desahogarse y de exponer su propia conducta con respecto de la poesía, su pensamiento político, y su vida personal sin haber llegado a una resolución en ese momento traumático.

El proceso que enfrenta Neruda en el 56, diría, es una especie de muerte simbólica en su vida personal (cuando termina con Delia) y en su cosmovisión política. No se encara con la muerte de verdad - aunque tiene un roce con la muerte que describe en "Laringe" y medita sobre la muerte en "Estación Inmóvil" en Estravagario - pero sí con pasos psicológicos y síntomas que el individuo enfrenta cuando se entera que se está muriendo. Las etapas por las que pasa el sujeto poético no obedecen a las que señala Elisabeth Kübler-Ross en su clásico libro sobre morir y la muerte (On Death and Dying) pero sí se ven iluminadas gracias a las categorías de la autora. De hecho, Estravagario mismo nos invita a seguir el itinerario del hablante que, ante el remezón personal y

${ }^{10}$ Hernán Loyola, "Neruda Moderno / Neruda Posmoderno", 2004, p. 16.

${ }^{11}$ No sin razón, Alain Sicard ve en Estravagario una puesta en escena de la crisis que atravesaron los comunistas después de las revelaciones de Jruschov. "Veíamos ingenuamente el estalinismo como una excrecencia aberrante pero pasajera, cuyo carácter canceroso no sospechábamos, o no queríamos reconocer, un tumor que la historia había generado, pero que ella, en su infinita sabiduría - y el dios de la Dialéctica mediante- ya había extirpado", p. 75. Evidentemente, como lo indica Sicard, el proceso de enfrentarse con las revelaciones de Jruschov y sus implicaciones políticas y personales comienza con Estravagario pero se elabora en varios libros posteriores. A mi entender no se empieza a resolver en la obra de Neruda sino hasta Memorial de Isla Negra (1964). Si se soluciona o no adecuadamente es otro tema sobre el que habría que haber más estudios, de ángulos diferentes, como los de Sicard y de Loyola. El artículo de Sicard cava hondo en el tema de la crisis y estimula a pensar en su impacto en el vate. "Pablo Neruda: Divagaciones y Regresos", 1999: 74-79. 
político, se siente a ratos confundido, perdido, incierto, algo reconfortado, deprimido y optimista. Esto se debe a los pasos que señala KüblerRoss, pero también al amor que siente por Matilde. Lo que emerge es un cuadro complicado por estos conflictos afectivos.

\section{El aislamiento como momento en la dialéctica}

Los poemas en Estravagario se agrupan en seis categorías provisorias: el silencio (que va de la mano del aislamiento); la muerte como tal; Matilde; la naturaleza como fundamento esencial; el yo y el otro (o los muchos yo que somos); y los recuerdos que tiene el poeta del Sur. Aprovechándose de este impasse en su vida, Neruda vuelve con vigor a la naturaleza y a Matilde para defenderse del desequilibrio que percibe. Después de ese primer caligrama que aparece en el poemario y que recuerda los versos de Apollinaire, Reverdy y Huidobro, y que representa, a mi juicio, el alcance de la poética moderna de Neruda, el lector pasa al aislamiento y el silencio como fase inicial en que el vate absorbe el golpe de las revelaciones de Jruschov y la ruptura final con La Hormiga.

Como lo sabe todo lector atento de la obra nerudiana, el segundo poema, "Pido Silencio", se establece como poema-tesis del libro y de esta nueva etapa.

\section{Pido Silencio}

Ahora me dejen tranquilo.

Ahora se acostumbren sin mí.

Yo voy a cerrar los ojos.

Y sólo quiero cinco cosas, cinco raíces preferidas.

Una es el amor sin fin.

Lo segundo es ver el otoño.

No puedo ser sin que las hojas vuelen y vuelvan a la tierra.

Lo tercero es el grave invierno, la lluvia que amé, la caricia del fuego en el frío silvestre. 
En cuarto lugar el verano redondo como una sandía.

La quinta cosa son tus ojos, Matilde mía, bienamada, no quiero dormir sin tus ojos, no quiero ser sin que me mires: yo cambio la primavera por que tú me sigas mirando.

Amigos, eso es cuanto quiero. Es casi nada y casi todo.

Ahora si quieren se vayan.

He vivido tanto que un día tendrán que olvidarme por fuerza, borrándome de la pizarra: mi corazón fue interminable.

Pero porque pido silencio no crean que voy a morirme: me pasa todo lo contrario: sucede que voy a vivirme.

Sucede que soy y que sigo.

No será, pues, sino que adentro de mí crecerán cereales, primero los granos que rompen la tierra para ver la luz, pero la madre tierra es oscura: y dentro de mí soy oscuro: soy como un pozo en cuyas aguas la noche deja sus estrellas y sigue sola por el campo.

Se trata de que tanto he vivido que quiero vivir otro tanto.

Nunca me sentí tan sonoro, nunca he tenido tantos besos. 
Ahora, como siempre, es temprano.

Vuela la luz con sus abejas.

Déjenme solo con el día.

Pido permiso para nacer ${ }^{12}$.

Pedir silencio y buscar una soledad necesaria para recuperarse y redefinirse se comunica desde un comienzo pero como parte de un proceso dialéctico. El mismo acto de escribir estos versos supone desde ya un intento de describir el proceso de desahogo. En verdad, no lo dejamos "tranquilo" al poeta ni nos acostumbramos sin él, desde luego, sino que presenciamos la crisis que lo asedia, como proceso afectivo volcado hacia afuera. Exteriorizado en los versos, este acto llega a ser una catarsis. Frente a la muerte real (biológica) y la muerte simbólica (las noticias del XX Congreso), Neruda vuelve entonces a cinco cosas indispensables en su vida que le servirán en este momento de reclusión y desahogo: "el amor sin fin" — que pareciera referirse al amor por el prójimo (el amor social) así como el amor por la vida-, el otoño, el "grave invierno", el verano, y finalmente, el amor de Matilde. Y estas cosas vitales le permiten al menos mantener las fuerzas necesarias para tratar de superar la situación en la que se halla. "He vivido tanto que un día / tendrán que olvidarme por fuerza, / borrándome de la pizarra / mi corazón fue interminable" (19). Lo que llama la atención aquí es el contraste entre el futuro ("tendrán"), que subraya su empeño, y el pasado ("fue") que se asociaría con la imagen pública de Neruda hasta 1956. El pasado amenaza con socavar los anhelos futuros del poeta y con anunciar su derrota, pero justo después agrega estos versos: "Pero porque pido silencio / no crean que voy a morirme: / me pasa todo lo contrario: / sucede que voy a vivirme" (19). Aquí queda claro que el silencio enunciado en sus versos se define como paso vital para "revivirse", pero en este momento el encierro (compartido con Matilde) y la introspección siguen vigentes. De ahí que comente a continuación, "Sucede que soy y que sigo", que difiere notablemente del Neruda de "Walking Around". El sujeto poético en Residencia en la Tierra se encuentra atrapado y enajenado en Buenos Aires y no halla salida. Este hablante, en cambio, reconoce que va a poder vencer su condición anímica en algún momento.

12 Pablo Neruda, Estravagario, edición y notas de Hernán Loyola, prólogo de Federico Schopf, 2003 [1958]), pp. 18-20. Todas las citas a continuación vienen de esta edición. 
La negación ante la muerte, sostiene Kübler-Ross, "funciona como mitigante después de haber recibido unas noticias inesperadamente impactantes; le permite al paciente reponerse y, con tiempo, movilizar otras defensas menos radicales"13. Este es, evidentemente, el silencio que pide Neruda: la tranquilidad y reserva para reponerse. No es inusual, dice la psicóloga, que después de este momento de reflexión y catarsis el paciente quiera comunicarse con alguien sobre la crisis (o la muerte). Y escribir sobre la crisis en Estravagario llega a ser parte íntegra de "revivirse". Por eso Neruda cierra el poema con estos versos: "Déjenme solo con el día. / Pido permiso para nacer" (20). Como lo sabe todo lector voraz de Neruda, esta idea tiene larga data en su obra. Por ejemplo, en "Naciendo en los Bosques" en la Tercera Residencia, el hablante afirmaba con cierto optimismo moderno después de la desolación de las residencias: "para nacer he nacido / para encerrar el paso de cuánto se aproxima"14. Volver a inventarse es una parte inextricable de la obra nerudiana ${ }^{15}$.

Pero como también lo sabe todo aficionado a sus versos, esa reinvención de sí mismo casi siempre se da gracias a una musa. El que diga que "h[a] vivido / que quier[e] vivir otro tanto" se debe, como apunta a las claras en "Pido Silencio", a que "nunca h[a] tenido tantos besos". De hecho, es gracias a Matilde que nunca se ha sentido "tan sonoro", inclusive en esta época de silencio declarado (20). Como lo ha comentado Hernán Loyola, la importancia de Matilde en la vida de Neruda no se puede subestimar, sobre todo en momentos así. Siendo la primera mujer a la que el versificador le dedica poemarios, el amor que le ofrece al poeta es maduro y hondo y le proporciona el élan vital para hacer frente a su crisis ${ }^{16}$. Esto recuerda los comentarios de Erich Fromm en su libro El Arte de Amar (The Art of Loving): "el amor maduro es una

${ }^{13}$ Elisabeth Kübler-Ross, On Death and Dying, 1969, pp. 35. La traducción del inglés es mía.

14 Pablo Neruda, Tercera Residencia, 1983, 18.

15 Véase "Pablo Neruda: Entre lo Inhabitado y la Fraternidad", de Alain Sicard, 2010), pp. xxix-liv. Véase también Hernán Loyola, "Los Modos de Autorreferencia en la Obra de Pablo Neruda" http://www.neruda.uchile.cl/critica/ hloyolamodos.html, y "Punto de Vista y Recodificación en los Poemas de Autoexégesis de Pablo Neruda" de Jaime Alazraki, 1978, pp. 184-197.

16 Hernán Loyola, "El Ciclo Nerudiano 1958-1967: Tres Aspectos" http://www.neruda.uchile.cl/critica/hloyola.html. 
unión bajo la condición de preservar la integridad del individuo, la individualidad de uno. El amor es un poder activo en el hombre; un poder que rompe las barreras que separan al hombre del prójimo, que lo une a otros; el amor lo ayuda a superar su sentido de aislamiento y separación, sin embargo le permite ser quien es, retener su integridad" ${ }^{17}$. Ese es el tipo de amor que le proporciona al poeta el fundamento para aguantar la crisis con el humor e ironía que se aprecian en varios poemas e ilustraciones en Estravagario.

La imagen que acompaña el poema remite humorísticamente y en toda seriedad a la contradicción operante que lo domina: el hablante pide silencio, pero nunca se ha sentido tan "sonoro". La ilustración de la trompa pareciera servir aquí de tropo visual de la voz del poeta, señalando así tanto el talento, la fuerza, y la sutileza de su don poético, como, paradójicamente, el abandono del instrumento que en cualquier momento puede retomar para "vivirse".

En "A Callarse", el silencio como solución momentánea ante las revelaciones del XX Congreso, se desplaza del ámbito personal al colectivo conectando así la vida del poeta con el momento histórico.



Fig. 1 de "Pido Silencio" (Estravagario, 1958)

${ }^{17}$ Erich Fromm, The Art of Loving, 1956, pp. 20-21. La traducción del inglés es mía. 


\section{A Callarse}

Ahora contaremos doce $\mathrm{y}$ nos quedamos todos quietos.

Por una vez sobre la tierra no hablemos en ningún idioma, por un segundo detengámonos, no movamos tanto los brazos.

Sería un minuto fragante, sin prisa, sin locomotoras, todos estaríamos juntos en una inquietud instantánea.

Los pescadores del mar frío no harían daño a las ballenas y el trabajador de la sal miraría sus manos rotas.

Los que preparan guerras verdes, guerras de gas, guerras de fuego, victorias sin sobrevivientes, se pondrán con sus hermanos por la sombra, sin hacer nada.

No se confunda lo que quiero con la inacción definitiva:

la vida es sólo lo que se hace, no quiero nada con la muerte.

Si no pudimos ser unánimes moviendo tanto nuestras vidas, tal vez no hacer nada una vez, tal vez un gran silencio pueda interrumpir esta tristeza, este no entendernos jamás y amenazarnos con la muerte, tal vez la tierra nos enseñe cuando todo parece muerto y luego todo estaba vivo.

Ahora contaré hasta doce y tú te callas y me voy (22-23). 
Con el humor leve tanto al comienzo como al final del poema, se crea una distancia necesaria entre el tema abordado y el hablante para así aprovechar este momento en la dialéctica. Lo que parece ser en un principio un juego de niños - "Ahora contaremos hasta doce / y nos quedamos todos quietos"- se vuelve un proyecto social serio. Que nosotros "no hablemos", "no movamos" nos permitirá, dice el poeta, estar juntos "en una inquietud instantánea" (22-23). Esta unidad colectiva, al ser "instantánea" e "inquietud", apunta necesariamente hacia una superación no muy definida pero latente. Anota nuevamente el afán de superar el estado de cosas pero sin ser explícito sobre ese plan. "No se confunda lo que quiero / con la inacción definitiva:" dice, "la vida es sólo lo que se hace, / no quiero nada con la muerte" (23). Reiteración de la postura en "Pedir Silencio", esta inmovilidad que dista de la que describe magistralmente en "Estación Inmóvil" afirma la voluntad de reflexionar y de reinventarse en el silencio. Haciendo eco de la desesperación sentida en la época de la guerra fría con la proliferación de armas nucleares, profiere lo siguiente: "Si no pudimos ser unánimes / moviendo tanto nuestras vidas, / tal vez no hacer nada una vez, / tal vez un gran silencio / pueda interrumpir esta tristeza, / este no entendernos jamás / amenazarnos con la muerte, / tal vez la tierra nos enseñe / cuando todo parece muerto / y luego todo estaba vivo" (23). El hablante recurre a la otra musa - la naturaleza - para buscar explicaciones por el estado de la humanidad como tal y por sus propias circunstancias personales. Neruda parecería estar muerto en su inmovilidad instantánea e inquieta, pero gracias a Matilde y la naturaleza está en el proceso de "revivirse".

Como la trompa (Fig. 1), este candado resulta inútil sin la intervención y ánimo humanos. La llave — la clave - no aparece en el dibujo, y así le veda el paso al intruso, al lector. Análoga a la cara del poeta, la boca se puede cerrar o abrir así como la trompa se puede tocar o dejar abandonada. La imagen, entonces, remata el tema de guardar silencio ("un gran silencio" compartido) al establecer esos dos vínculos. También podría dar a entender que la solución (la llave) que se anda buscando en este mundo que no pareciera tener muchas soluciones en plena época de Guerra Fría, es desconocida, imperceptible en este momento histórico. En ambos casos la ilustración logra comunicar mensajes parecidos a los del poema, siendo así ejemplos de imágenes que se asocian, 


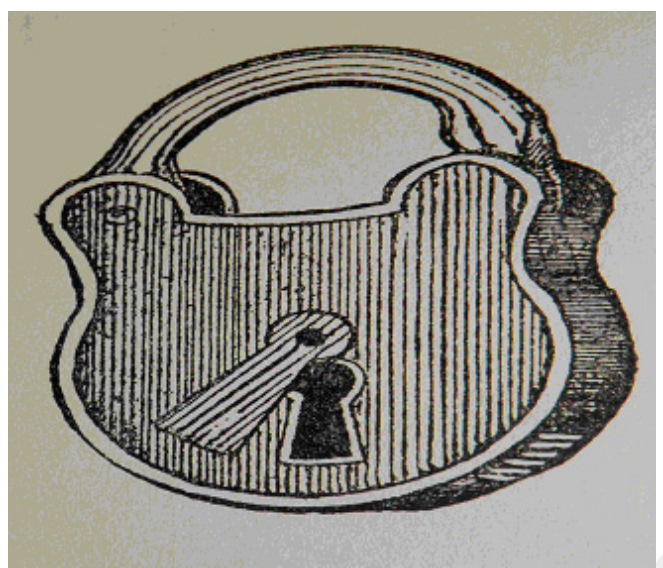

Fig. 2, “A Callarse” (Estravagario, 1958)

como señala María Luisa Fischer, directamente con los poemas. Ambas ilustraciones serían, siguiendo el patrón del libro de llamar la atención a su condición de "producto de la industria editorial", objetos que contrastan con, pero se ligan a, los textos dinámicos ${ }^{18}$.

\section{"Estación Inmóvil"}

Si es cierto que hay poemas en Estravagario que lindan con la muerte simbólica, otros, como "Laringe" y "Estación Inmóvil" se enfocan en su mortalidad y la exploración de la muerte que se manifestará en la obra tardía de Neruda. El enfrentamiento con la muerte simbólica debido a la crisis que provoca el XX Congreso del PCUS lo obliga necesariamente a encararse con su propia finitud $\mathrm{y}$, de ser posible, imaginar un fin menos penoso y terrorífico. Si la muerte es algo que los seres humanos no son capaces de imaginar porque el pensamiento en sí no puede pensar en su desaparición definitiva, como señala Zygmunt Bauman, sí se puede conjeturar a base del conocimiento de la naturaleza, pero siempre como espectador ${ }^{19}$. En el poema magistral "Estación Inmóvil"

${ }^{18}$ María Luisa Fischer, Neruda: Construcción y Legados de una Figura Cultural, 2008, pp. 169, 162. Léase, en particular, "Para leer un libro ilustrado", pp. 156-176.

${ }^{19}$ Zygmunt Bauman, “Living with Death”, 1992, pp. 12-50. 
Neruda, como su gran amigo-poeta Nazim Hikmet, busca proporcionarse a sí mismo una visión de su muerte imaginada ya fundamentalmente desvinculada de sus connotaciones simbólicas y desprovista de la dimensión política que sirve de referente en varios de los otros poemas de Estravagario. La crisis compartida con Matilde cala tan hondo que lo hace concebir su propia muerte.

\section{Estación Inmóvil}

Quiero no saber ni soñar.

Quién puede enseñarme a no ser, a vivir sin seguir viviendo?

Cómo continúa el agua?

Cuál es el cielo de las piedras?

Inmóvil, hasta que detengan las migraciones su apogeo y luego vuelen con sus flechas hacia el archipiélago frío.

Inmóvil, con secreta vida como una ciudad subterránea para que resbalen los días como gotas inabarcables: nada se gasta ni se muere hasta nuestra resurrección, hasta regresar con los pasos de la primavera enterrada, de lo que yacía perdido, inacabablemente inmóvil y que ahora sube desde no ser a ser una rama florida (63-64).

Desde el comienzo este poema tiene algo de "Lo Fatal" de Darío pero difiere de los versos del nicaragüense al querer hallar la inmortalidad precisamente en el seno de la naturaleza que abre y cierra la vida (que se aprecia en la antítesis que es el título del poema). En la primera estrofa se autorretrata como espectador, testigo de su propia muerte que quisiera "vivir sin seguir viviendo" que es, siguiendo el análisis de Bauman, imaginar lo inimaginable (nuestra propia muerte). Ese concepto predilecto de Neruda, la inmovilidad, que suele representar un momento 


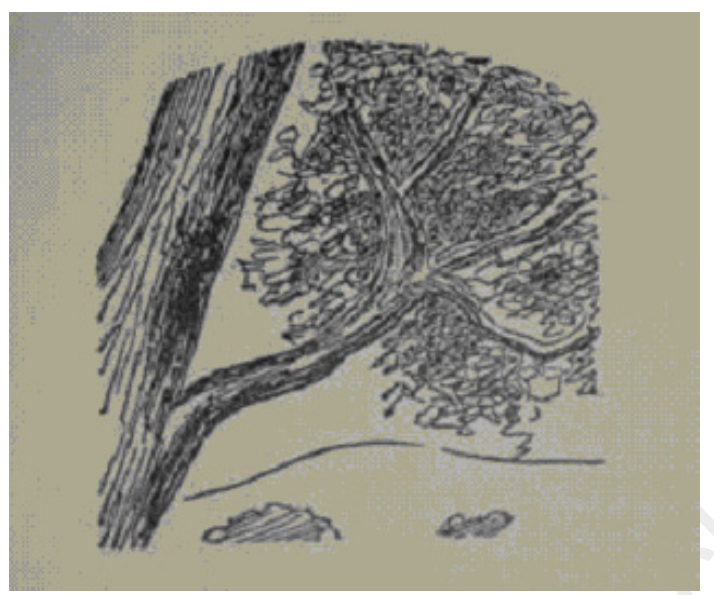

Fig. 3, "Estación Inmóvil” (Estravagario, 1958)

en la dialéctica, una fricción momentánea que luego da paso a su superación, interviene, podríamos decir, como metáfora de la muerte. La vida no se acaba; no nos morimos. Como la naturaleza — como el agua y las piedras, como la materia de la tercera ley de la termodinámica - somos inmortales al pasar de una forma de materia a otra. El ser "yacía perdido" y había llegado a "no ser" hasta que se volvió "rama florida". En efecto, la imagen que va con "Estación Inmóvil" pareciera confirmar esa lectura.

La rama florida del árbol yace sobre lo que puede ser la tierra o bien un arroyo habiéndose rehabilitado - se puede inferir - gracias a la transmutación que le brinda la naturaleza. Como el árbol del Canto General también comunica el hecho de que muerto sigue viviendo como parte de la humanidad.

"Estación Inmóvil" así como "Laringe" representan textos en que el poeta va más allá de la crisis pero en la dirección contraria. No se trata de una sublimación del contexto que enfrenta, sino, más bien, un intento de ficcionalizar su propia (in)existencia. El grueso de los poemas en Estravagario, en cambio, plasma la crisis simbólica que asedia a Neruda y anda buscando una solución en la vida, y concretamente en otros seres humanos. Nuestras vidas, dice Bauman en un eco de Marx, cobra sentido gracias a los seres que nos son queridos y esas relaciones nos permiten darle sentido a la vida ${ }^{20}$.

${ }^{20}$ Bauman “Living with Death”, 1992, p. 37. 


\section{Los muchos que somos}

Se podría afirmar que Estravagario marca el momento en el que Neruda busca compartir su soledad y su crisis con los lectores. Llega a una aceptación parcial de su propia finitud pero, por eso mismo, vuelve insistentemente a la afirmación de la vida tanto en términos personales como sociales. La primera tentativa de enfrentar la crisis en el plano personal es reconocer que como seres humanos nuestras vidas consisten en varias muertes y varios nacimientos.

En "Regreso a una Ciudad", por ejemplo, en que vuelve al Oriente pero con Matilde, sobresalen las preguntas que persiguen al hablante al comienzo del poema: "A qué he venido? Les pregunto. / Quién soy en esta ciudad muerta?" Y unos versos después: "pero dónde, / pero dónde estuve, quién fui? / No entiendo sino las cenizas" (24). Si no entiende su identidad en la etapa residenciaria de su vida, sí llega a esta determinación en Estravagario: "Ahora me doy cuenta que he sido / no sólo un hombre sino varios / que cuantas veces he muerto, / sin saber cómo he revivido" (24-25). Si somos una acumulación de vidas y muertes en sucesión, volver a otra fase de nuestras vidas es, como afirma en el último verso del poema, como volver a una cárcel, es volver a ver la muerte. Por eso afirma en el presente, "regreso al amor de mi vida [Matilde]/ a lo que fui y a lo que soy" (25).

Pero para pasar al plano social, el reconocimiento de las muchas vidas y muertes que vivimos tiene que ir más allá del contexto individual. Poemas como "Regreso a una Ciudad" o "No tan Alto" presentan la muerte como un fenómeno momentáneo y dialéctico, pero al nivel del individuo. "[H]ay que darse un baño de tumba" reza el verso en "No tan Alto" y hacerlo "desde la tierra cerrada" para así "mirar hacia arriba el orgullo" (31, 33). Así, sostiene Neruda, "se aprende a ser" y "a morir" (33). Al compartir y aceptar esta condición humana ya estamos "cayendo / dentro del pozo de los otros seres", como lo pone en "Vamos Saliendo" (39). Es decir que aun un destino que pareciera ser, en la superficie, individual, es, a fin de cuentas, social y socializado.

Pero también se enfrenta con la muerte simbólica en el ámbito político en el núcleo de poemas imprescindibles que son "No me Pregunten", "Muchos Somos", y “Aquí Vivimos". En el primero se destaca la crisis personal y política abiertamente. 


\section{No me Pregunten}

Tengo el corazón pesado con tantas cosas que conozco, es como si llevara piedras desmesuradas en un saco, o la lluvia hubiera caído, sin descansar, en mi memoria.

No me pregunten por aquello. No sé de lo que están hablando. No supe yo lo que pasó.

Los otros tampoco sabían y así anduve de niebla en niebla pensando que nada pasaba, buscando frutas en las calles, pensamientos en las praderas y el resultado es el siguiente: que todos tenían razón y yo dormía mientras tanto. Por eso agreguen a mi pecho no sólo piedras sino sombra, no sólo sombra sino sangre.

Así son las cosas, muchacho, y así también no son las cosas, porque, a pesar de todo, vivo, y mi salud es excelente, me crecen el alma y las uñas, ando por las peluquerías, voy y vengo de las fronteras, reclamo y marco posiciones, pero si quieren saber más se confunden mis derroteros y si oyen ladrar la tristeza cerca de mi casa, es mentira: el tiempo claro es el amor, el tiempo perdido es el llanto.

Así, pues, de lo que recuerdo $\mathrm{y}$ de lo que no tengo memoria, de lo que sé y de lo que supe, 
de lo que perdí en el camino entre tantas otras cosas perdidas, de los muertos que no me oyeron y que tal vez quisieron verme, mejor no me pregunten nada: toque aquí, sobre el chaleco, y verán cómo me palpita un saco de piedras oscuras (46-47).

Poema confesional, arranca con el peso que ha tenido que cargar el sujeto poético ante las revelaciones de Jruschov: "Tengo el corazón pesado / con tantas cosas que conozco, / es como si llevara piedras / desmesuradas en un saco, / o la lluvia hubiera caído, / sin descansar, en mi memoria". Y en la segunda estrofa agrega lo siguiente: "No me pregunten por aquello. / No sé de lo que están hablando. / No supe yo lo que pasó" (46). El intento es de dar un testimonio franco y desgarrador del momento histórico y del impacto devastador que tuvo en el hablante. Y aunque trate luego de negar momentáneamente la crisis por la que está pasando - “y si oyen ladrar la tristeza / cerca de mi casa, es mentira: / el tiempo claro es el amor, / el tiempo perdido es el llanto"vuelve a afirmar el dolor de la crisis al final del poema. "[M]ejor no me pregunten nada: / toquen aquí, sobre el chaleco", dice, "y verán cómo me palpita / un saco de piedras oscuras" (47). Por añadidura, lo que se nota es la culpabilidad subyacente que recorre el poema y que se expresa sucintamente en estos versos: "y el resultado es el siguiente: / que todos tenían razón / y yo dormía mientras tanto" (47). Los medios de comunicación en los países capitalistas que condenaban las purgas y los excesos del poder bajo Stalin "tenían razón” y Neruda hacía caso omiso de esas denuncias.

Aunque no cuadre completamente con el caso de Neruda, esta culpabilidad coincide con la etapa de "negociaciones" con la muerte que percibe Kübler-Ross. Según la psicóloga, el paciente trata de posponer la muerte y buscar cumplir con metas personales, como por ejemplo, cantar en una última ópera o ir a la boda del hijo. Tras estas promesas que hace el paciente subyace lo que Kübler-Ross denomina una "culpabilidad silenciosa"21. Estancado todavía en la confusión, la sacudida emocional, y a punto de querer aceptar las realidades de la época

${ }^{21}$ Elisabeth Kübler-Ross, On Death and Dying, 1969, pp. 73-74. 


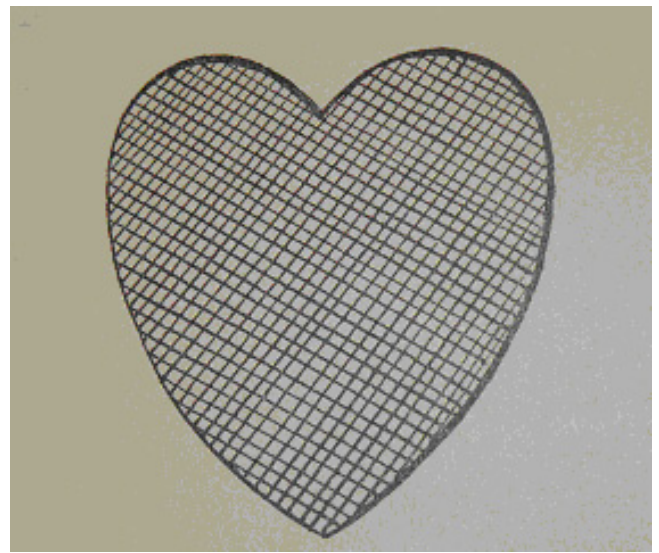

Fig. 4, "No me Pregunten" (Estravagario, 1958)

estaliniana, queda claro que Neruda se siente culpable por haber sido cómplice. Reina en él una "culpabilidad silenciosa" y por eso mismo una suerte de impotencia frente a las revelaciones. ¿Cómo "revivirse" en estas condiciones? Porque pese a que afirma "vivo, / y mi salud es excelente, / me crecen el alma y las uñas" (47), lo que sobresale y que domina en el poema es el peso insostenible de los crímenes del régimen de Stalin. Frente a esta crisis hondamente personal y política Neruda no halla soluciones de momento, no encuentra salidas, ni críticas que le sirvan para vencerla.

También en este caso la imagen que viene con el poema representa la sinécdoque que predomina en el poema: el pesar del poeta ante las revelaciones inesperadas sobre el régimen de Stalin. La duda que emerge es si las rayas en el dibujo sirven para simbolizar el corazón oscuro en el sentido literal o figurativo (aunque puede ser ambas cosas). $\mathrm{Si}$ se trata de lo último, las rayas — que vienen a parecerse a una mallacomunicarían el mensaje del poema de una manera aun más fidedigna. Por un lado el corazón se podría ver como protegido de las revelaciones y tal vez de los ataques de sus "derroteros". Por otro lado, se podría identificar como el "corazón pesado" al que se refiere el hablante. Se subraya, en todo caso, la pesadumbre, incertidumbre y vulnerabilidad del sujeto poético ante la crisis.

En ese estado irresuelto se presenta el hablante en "Muchos Somos". El humor en sí subraya la brecha entre la crisis y su solución. 
"De tantos hombres que soy, que somos, / no puedo encontrar ninguno: / se me pierden bajo la ropa, / se fueron a otra ciudad" (49). En verdad lo que logra es postergar la resolución de la crisis con el humor. De ahí que se pregunte: "Qué debo hacer para escogerme? / Cómo puedo rehabilitarme?" (50). Rehabilitarse, volver a nacer, o revivirse: lo cierto es que tantea maneras de llevar a cabo este cambio pero recae en la incertidumbre. "[Y] así yo no sé quién soy," comenta, "no sé cuantos soy o seremos" (50).

\title{
Reviviéndose
}

Parece divisar la salida de esta encrucijada afectiva en el gran poema "Aquí Vivimos" y así evitar las dos últimas etapas psicológicas que describe Kübler-Ross - la depresión y la aceptación final. En términos simbólicos, caer en una depresión psicosomática y aceptar la muerte definitiva sería el equivalente de rendirse en el terreno de la política y, por ende, en el plano personal. Sería, en rigor y siguiendo el ejemplo de tales ex comunistas como Italo Calvino, E. P. Thompson, Howard Fast, Jorge Amado entre otros muchos, abandonar la causa comunista después del XX Congreso del PCUS. Al ser así, la depresión devendría personal y lo confrontaría con la aceptación de la muerte.

Pero Neruda toma otro camino. El punto de arranque en "Aquí Vivimos" es su refugio en Isla Negra, lugar de encuentro vital con la naturaleza y amparo con su amada Matilde.

\author{
Aquí Vivimos \\ Yo soy de los que viven \\ a medio mar y cerca del crepúsculo, \\ más allá de esas piedras. \\ Cuando yo vine \\ y vi lo que pasaba \\ me decidí de pronto. \\ El día ya se había repartido, \\ ya era todo de luz \\ y el mar peleaba \\ como un león de sal, \\ con muchas manos.
}


La soledad abierta allí cantaba, y yo perdido y puro, mirando hacia el silencio abrí la boca, dije:

'Oh madre de la espuma, soledad espaciosa, fundaré aquí mi propio regocijo, mi singular lamento’.

Desde entonces jamás me defraudó una ola, siempre encontré sabor central de cielo en el agua, en la tierra, y la leña y el mar ardieron juntos durante los solitarios inviernos.

Gracias doy a la tierra por haberme esperado a la hora en que el cielo y el océano se unen como dos labios, porque no es poco, no es así? haber vivido en una soledad y haber llegado a otra sentirse multitud y revivirse solo.

Amo todas las cosas, $\mathrm{y}$ entre todos los fuegos sólo el amor no gasta, por eso voy de vida en vida, de guitarra en guitarra, y no le tengo miedo a la luz ni a la sombra y porque casi soy de tierra pura tengo cucharas para el infinito.

Así, pues, nadie puede equivocarse, no hallar mi casa sin puertas ni número, allí entre las piedras oscuras frente al destello de la sal violenta, allí vivimos mi mujer y yo, allí nos quedaremos. Auxilio, auxilio! Ayuden! Ayúdennos a ser más tierra cada día! Ayúdennos a ser más espuma sagrada, más aire de la ola! (52-54). 
Vuelve al mar y a su musa para buscar la resolución. En la "madre de la espuma, / soledad espaciosa" dice que fundará su "propio regocijo, [su] singular lamento" (53). Esto parecería ser un retorno a la soledad que puebla Residencia en la Tierra, pero la vuelve individualidad socializada. "Gracias doy a la tierra / por haberme / esperado / a la hora en que el cielo y el océano / se unen como dos labios, / porque no es poco, no es así? haber vivido / en una soledad y haber llegado a otra, / sentirse multitud y revivirse solo" (53). Ha abandonado la soledad residenciaria para llegar a esta otra más satisfactoria. Se siente "multitud" en tanto ser humano pero también en tanto comunista que enfrenta los mismos dilemas y las mismas incógnitas que sus camaradas en el '58. Y se podría sacar la conclusión, como lo han hecho varios críticos, de que "revivirse solo" señala desde ya una nueva concepción del individuo y de la individualidad y su compromiso con la política. Sin embargo, aunque pareciera ser una dialéctica magnífica — ser multitud y estar solo- el proceso no ha llegado aún a su sublimación. Para ponerlo en términos marxistas, es la unión de dos conceptos antitéticos (la compenetración de opuestos) que no ha dado paso a la transformación aún. De pasar ya a una resolución tendría que decir "vivir solo" o, para ser leal al neologismo nerudiano, "vivirse solo". Quiero decir que ese verso se formularía así: "sentirse multitud, vivirse solo". Lo que se asemeja a una resolución del apuro personal resulta ser, entonces, la reformulación de la relación entre el individuo en crisis que, sin embargo, no ha renunciado a su compromiso político.

La ilustración que se compagina con "Aquí Vivimos" resulta ser más figurativa que las anteriores. Neruda ha elegido una tetera que puede representar una casa metafóricamente, con lo que parecieran ser el techo, la ventana (el pico de la tetera) y la puerta. Es, efectivamente, una tetera hecha casa (la de Isla Negra) "sin puertas ni número" prácticamente - ya que la puerta está cerrada con un pestillo — que esconde y protege el amor compartido con Matilde ("aquí vivimos mi mujer y yo"). De ahí emana la energía y la inspiración para acercarse a la multitud por medio de su obra y su compromiso social.

Sin embargo, en el ámbito personal no manifiesta haber aclarado la situación en la que se encuentra. En "Pastoral," por ejemplo, se expresa el proceso de buscar una nueva identidad. "[A] unque me esperen yo quiero esperarme, / yo también quiero verme" comenta acerca de este proceso inconcluso (57-58). Después de impartir lecciones de la vida, 


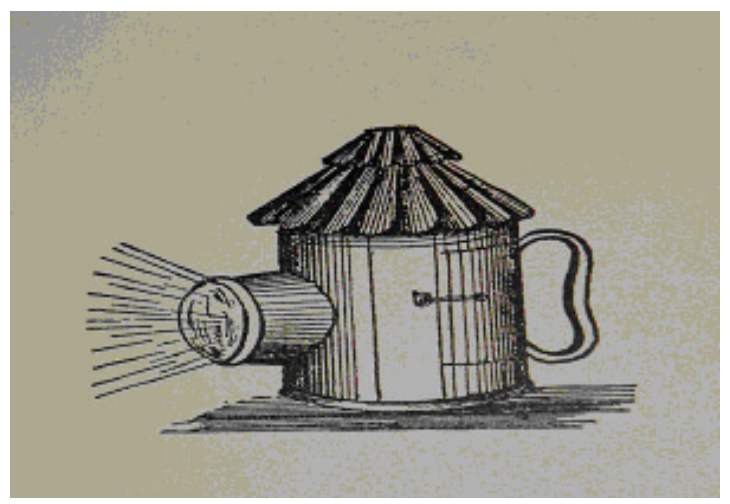

Fig. 5, “Aquí Vivimos” (Estravagario, 1958)

en "Sonata con algunos Pinos" acepta el cambio como parte íntegra de la vida - "es bueno cambiar de camisa / de piel de pelos de trabajo" (71) — y sabe cómo llegó a reconocerse, a cobrar su identidad, pero llega a la conclusión práctica e inconclusa de que hay que hacer "profesión terrestre" y tocar "tierra con el alma" (72). De ahí pasa nuevamente al desasosiego que lo atormenta y al asalto de interrogantes en poemas tales como "Itinerarios" o "Adiós a París". En resumidas cuentas, a partir de "Aquí Vivimos" se hilvanan las incertidumbres del sujeto poético con las tentativas de buscar en la naturaleza, los recuerdos de su infancia en el Sur, y en Matilde las fuerzas para superar la crisis en la que se halla sin encontrar salida alguna. No pasa, por cierto, a la depresión ni a la aceptación definitiva ante la muerte simbólica, sino que permanece en la dialéctica de "sentirse multitud" y "revivirse". Esto se constata en los últimos y determinantes versos de Estravagario (en "Testamento de Otoño"): "Mientras se resuelven las cosas / aquí dejé mi testimonio, / mi navegante estravagario / para que leyéndolo mucho / nadie pudiera aprender nada, / sino el movimiento perpetuo / de un hombre claro y confundido, / de un hombre lluvioso y alegre, / enérgico y otoñabundo" (131). "[M]ovimiento perpetuo" en la dialéctica, no ha llevado aún a este "hombre claro y confundido" a un avance más allá de la crisis que lo aflige ${ }^{22}$.

22 "Testamento de Otoño" (122-132) cierra el libro con una nota burlona pero también seria. Se trata de un "testamento" de un hombre que tiene 54 años ("otoñabundo" según el poeta) que da cuenta de una época recorrida en su vida, de la vida y muerte (simbólica) del Neruda moderno (no posmoderno). Por otro 
Esa transformación definitiva no se da, según estimo, hasta seis años después de la publicación de Estravagario con Memorial en Isla Negra. Es en éste que Neruda inaugura su nueva y relativamente coherente modalidad autobiográfica e incluye la crisis plasmada en Estravagario como parte constitutiva de su vida, como otra muerte simbólica transitada. Es en Memorial que se destaca la nueva identidad posmoderna y se pone a "vivir" 23 . Es más: es en "El Episodio" que Neruda aborda su crítica más aguda contra el régimen de Stalin y afirma su compromiso renovado con el Partido Comunista y con el destino de la "multitud".

\section{BIBLIOGRAFÍA}

Alazraki, Jaime. "Poética de la Penumbra en la Poesía más Reciente de Pablo Neruda". Revista Iberoamericana, Nos. 82-83 (enero-junio, 1973).

"Punto de Vista y Recodificación en los Poemas de Autoexégesis de Pablo Neruda". En Jaime Alazraki, Symposium (1978): 184-197.

Bauman, Zygmunt. "Living with Death". En Mortality, Immortality and Other Life Strategies. Stanford: Stanford University Press, 1992.

Benedetti, Mario. Los Poetas Comunicantes. México: Marcha, 1981.

Costa, René de. The Poetry of Pablo Neruda. Cambridge, MA: Harvard University Press, 1979.

Dawes, Greg. Poetas ante la Modernidad: Las Ideas Estéticas y Políticas de Vallejo, Huidobro, Neruda y Paz. Madrid: Editorial Fundamentos, 2009.

Durán, Manuel y Margery Safir. Earth Tones: The Poetry of Pablo Neruda. Bloomington: Indiana University Press, 1981.

Egbert, Donald G. "The Idea of 'Avant-garde' in Art and Politics". The American Historical Review, Vol. LXXIII, No 2 (1967): 339-366.

Fischer, María Luisa. Neruda: Construcción y Legado de una Figura Cultural. Santiago: Editorial Universitaria, 2008.

Fromm, Erich. The Art of Loving. New York: Harper \& Brothers Publishers, 1956.

lado, es un "testamento" en que hace un ajuste de cuentas y deja, como lo haría cualquier testamento, sus posesiones y, en este caso también, sus cargas anímicas a otros individuos. Así también se recalca la división entre el Neruda moderno y el posmoderno al emplear el pretérito en el primer caso, y el futuro en el segundo. Y el tiempo verbal del futuro señala desde ya, en los últimos versos del libro, una conceptualización y aceptación a medias de la muerte.

${ }^{23}$ Me refiero al estudio de Hernán Loyola sobre el Neruda posmoderno después del 56. No se trataría de un posmodernismo pleno y lleno, producto de la ideología dominante de la globalización, sino más bien de un posmodernismo de resistencia o, como lo pone Adolfo Sánchez Vázquez, un "socialismo posmoderno". 
Kübler-Ross, Elisabeth. On Death and Dying. New York: MacMillan Publishers, 1969.

Loyola, Hernán. "El Ciclo Nerudiano 1958-1967: Tres Aspectos" http://www. neruda.uchile.cl/critica/hloyola.html.

"Neruda Moderno / Neruda Posmoderno". Centro de Estudios Miguel Enríquez (2004). http://www.archivochile.com/Homenajes/ neruda/sobre_neruda/homenajepneruda0030.pdf.

"Neruda Posmoderno". A Contracorriente, Vol. 6, No 1 (Fall 2008): 1-14. www.ncsu.edu/acontracorriente.

"Los Modos de Autorreferencia en la Obra de Pablo Neruda". http:// www.neruda.uchile.cl/critica/hloyolamodos.html.

Neruda, Pablo. Estravagario. Buenos Aires: Losada, 1958.

Estravagario, edición y notas de Hernán Loyola, prólogo de Federico Schopf. Buenos Aires: Debolsillo, 2003 [1958].

Tercera Residencia, tercera edición. Barcelona: Seix Barral, 1983.

Paz, Octavio. Los Hijos del Limo: Del Romanticismo a la Vanguardia, quinta edición. Barcelona: Seix Barral, 1998.

Poggioli, Renato. The Theory of the Avant-Garde. Cambridge, M.A.: Harvard University Press, 1968.

Rodríguez Monegal, Emir. "El Sistema del Poeta". Revista Iberoamericana, Nos. 82-83 (enero-junio, 1973).

Sánchez Vázquez, Adolfo. "Posmodernidad, Posmodernismo y Socialismo". Campus virtual. http://168.96.200.17/gsdl/cgi-bin/library? $=\mathrm{d}-000$ 00---0bcvirt--00-0-0--0prompt-10---4------0-11--1-es-50---20-help--00031-001-1-0utfZz-8-00\&cl=CL3.1.1\&d=HASH2c2148cfad2b4eef1a $\mathrm{e} 965 \& \mathrm{x}=1$.

Schopf, Federico. "La (In)certidumbre en la Obra Tardía de Neruda", No 94, Estudios Públicos (otoño 2004): 165-193.

Sicard, Alain. “"El Hijo de la Luna': Crítica y Valoración del Sujeto Poético en la Obra de Pablo Neruda Posterior al Canto General". Coloquio Internacional sobre Pablo Neruda (la Obra Posterior a Canto General). Poitiers: Centre de Recherche Latino-americaines, 1979.

- "Pablo Neruda: Divagaciones y Regresos". América sin Nombre (diciembre de 1999): 74-79.

- "Pablo Neruda: Entre lo Inhabitado y la Fraternidad". En Pablo Neruda: Antología General, a cargo de Hernán Loyola. Lima: Real Academia Española/Asociación de Academias de la Lengua Española, 2010, xxix-liv.

Weir, David. Anarchy \& Culture: the Aesthetic Politics of Modernism. Amherst: University of Massachusetts Press, 1997. 